\title{
The Role of Education and Intellectual Activity on Cognition
}

\author{
Jeanine M. Parisi, ${ }^{1}$ George W. Rebok, ${ }^{1,2}$ Qian-Li Xue,, ${ }^{2,3}$ Linda P. Fried, ${ }^{4}$ Teresa E. Seeman, ${ }^{5}$ \\ Elizabeth K. Tanner, ${ }^{2,6}$ Tara L. Gruenewald, ${ }^{7}$ Kevin D. Frick, ${ }^{1}$ and Michelle C. Carlson ${ }^{1,2}$
}

${ }^{1} J o h n s$ Hopkins Bloomberg School of Public Health, Baltimore, MD 21205, USA

${ }^{2}$ Johns Hopkins Center on Aging and Health, Johns Hopkins University, Baltimore, MD 21205, USA

${ }^{3}$ Johns Hopkins School of Medicine, Baltimore, MD 21205, USA

${ }^{4}$ Mailman School of Public Health, Columbia University, New York, NY 10032, USA

${ }^{5}$ David Geffen School of Medicine, University of California at Los Angeles, CA 90095, USA

${ }^{6}$ Johns Hopkins School of Nursing, Baltimore, MD 21205, USA

${ }^{7}$ Davis School of Gerontology, University of Southern California, Los Angeles, CA 90089, USA

Correspondence should be addressed to Jeanine M. Parisi, jparisi@jhsph.edu

Received 2 April 2012; Revised 14 June 2012; Accepted 24 June 2012

Academic Editor: Denis Gerstorf

Copyright () 2012 Jeanine M. Parisi et al. This is an open access article distributed under the Creative Commons Attribution License, which permits unrestricted use, distribution, and reproduction in any medium, provided the original work is properly cited.

\begin{abstract}
Although educational attainment has been consistently related to cognition in adulthood, the mechanisms are still unclear. Early education, and other social learning experiences, may provide the skills, knowledge, and interest to pursue intellectual challenges across the life course. Therefore, cognition in adulthood might reflect continued engagement with cognitively complex environments. Using baseline data from the Baltimore Experience Corps Trial, multiple mediation models were applied to examine the combined and unique contributions of intellectual, social, physical, creative, and passive lifestyle activities on the relationship between education and cognition. Separate models were tested for each cognitive outcome (i.e., reading ability, processing speed, memory). With the exception of memory tasks, findings suggest that education-cognition relations are partially explained by frequent participation in intellectual activities. The association between education and cognition was not completely eliminated, however, suggesting that other factors may drive these associations.
\end{abstract}

\section{The Role of Education and Intellectual Activity on Cognition}

Cognitive enrichment early in life may account for some of the variation in cognitive ability in adulthood. Consistently, higher educational attainment is associated with greater levels of cognitive performance [1-5], as well as with a reduced risk of dementia and Alzheimer's disease [6-9]. Although the exact mechanisms are unclear, one possibility is that educational experiences provide the foundation for continued intellectual stimulation across the life course, resulting in improved cognitive functioning in late adulthood. Prior research findings contribute to the plausibility of this assumption. First, educational attainment is often associated with greater participation in various lifestyle activities $[10,11]$, especially those that are cognitively demanding [12-14]. Second, the beneficial effects of maintaining an engaged lifestyle have been demonstrated across several studies, even when activities are introduced later in life [15-19].

Education may cultivate the knowledge, skills, and ability necessary for continued participation in intellectually demanding activities (e.g., reading, taking courses) well into later adulthood. According to the engagement hypothesis, in-dividuals who continuously place significant demands on their intellectual resources (i.e., through multiple and complex decisions, ill-defined problem solving) may maintain or even enhance cognitive potential $[3,20,21]$. Therefore, compared to other forms of lifestyle activity, greater participation in intellectually demanding activities may be especially beneficial for cognitive function $[3,10,14,20-24]$. For instance, Hultsch et al. [10] found that individuals who more frequently participated in novel information processing were less likely to show cognitive declines over time. Likewise, Ghisletta and colleagues [25] found that activities such as reading a book and playing games were related to changes in 
perceptual speed, whereas other forms of engagement (e.g., physical, social, and religious activities) were not associated with such changes. Conversely, activities low in cognitive stimulation, such as watching television, have been related to an increased risk of cognitive impairment [26]. Moreover, activities low in cognitive demand may be more prevalent among those with lower educational attainment [27].

Although several studies have explored the independent contributions of education or activity on cognition, few studies have explored these factors in combination. The current study examines whether educational attainment and late-life activities contribute independently to cognitive performance or if education-cognition relations can be at least partly explained by participation in activities in adulthood. Specifically, our work is driven by the following assumptions: (1) education will be associated with cognition, such that individuals with higher levels of educational attainment will demonstrate better performance on cognitive measures; (2) older adults with higher levels of educational attainment will report being more active, especially in intellectually demanding activities; (3) intellectual activities will influence cognition, such that participation in intellectually demanding activities (as compared to other forms of activity) will be related to better cognitive performance, independent of education. Consequently, we expect that the association between education and cognition will be attenuated (not completely eliminated) once participation in a wide variety of lifestyle activities is considered [28, 29]. Further, we also expect that the effects will be greatest for intellectually demanding activities, as these may be more strongly associated with both education and cognition $[1-5,10,12-14]$.

We wish to be clear that this cross-sectional, correlational research does not allow us to establish the temporal ordering among variables and acknowledge that reciprocal relationships could be possible. Therefore, we cannot draw any conclusions regarding causal relationships between education, activity and cognition as implied by our theoretically based model (i.e., education leads to greater participation in activities, which in turn, promotes cognition). However, in the absence of longitudinal data, establishing associations among education, activity, and cognition allows us to better conceptualize plausible mechanisms for the promotion of cognitive health in adulthood.

\section{Methods}

We report data collected as part of the Baltimore Experience Corps Trial (see Fried and colleagues [30] for detailed description of recruitment procedures and study design), a community-based volunteer program designed as a health promotion model for older adults while simultaneously addressing the academic needs of elementary school children $[30,31]$. Briefly, in this program older adults (age 60 and older) are trained and placed into elementary school classrooms (kindergarten to third grade) to serve as mentors and tutors for young children. To be eligible to serve as a volunteer, individuals had to meet screening criteria for general cognitive status (as indicated by a score of greater than 23 on the Mini-Mental State Exam (MMSE)) [32]
TABLE 1: Demographic characteristics of sample.

\begin{tabular}{lccc}
\hline & $\%$ & $\mathrm{M}$ & $\mathrm{SD}$ \\
\hline Age (years) & & 67.49 & 5.95 \\
Education (years) & & 13.85 & 2.94 \\
$\quad$ Elementary school (K-8) & 2.3 & & \\
$\quad$ High school/equivalent (9-12) & 40.2 & & \\
$\quad$ College (13-16) & 41.2 & & \\
$\quad$ Postgraduate & 13.1 & & \\
$\quad$ Other & 1.1 & & \\
Income (past 12 months) & & & \\
$\quad$ Less than $\$ 5,000$ & 6.1 & & \\
$\quad \$ 5,000-14,999$ & 23.1 & & \\
$\quad$ S15,000-34,999 & 35.2 & & \\
$\quad \$ 35,000-74,999$ & 27.4 & & \\
$\quad \$ 75,000$ or greater & 6.8 & & \\
Sex & & & \\
$\quad$ Male & 15.4 & & \\
Female & 84.6 & \\
Race & & \\
African American & 90.5 & \\
European American & 5.1 & \\
\hline
\end{tabular}

and perform at a sixth grade reading level or higher on a measure of functional literacy, the Wide Range Achievement Test (WRAT-4) [33]. The data we report are based on baseline scores for measures before participants $(N=$ 702) were randomly assigned to one of two conditions: to the intervention (Experience Corps program) or to a lowactivity control group.

2.1. Sample. For purposes of the present analyses, individuals were included $(n=675)$ if they completed the Lifestyle Activities Questionnaire (LAQ) [16] and cognitive measures as part of the baseline assessment. Participants were, on average, 67 years of age ( $S D=5.95$, range $=60-89$ years), had 13.9 years of education ( $\mathrm{SD}=2.94$, range $=6-22$ years $)$, and were predominantly female $(84.6 \%)$ and African American (90.5\%) (Table 1). In addition, participants reported their current health as excellent, very good, or good (89.1\%) and displayed very low levels of depressive symptoms (as indicated by a score less than 5 on the 15 -item Geriatric Depression Scale; $\mathrm{M}=1.5$ symptoms; $\mathrm{SD}=1.7$ ) [34]. We have reported elsewhere that individuals who did not complete the LAQ at baseline tended to be older, reported poorer health, and demonstrated lower cognitive performance (as measured by the MMSE and WRAT- 4$)(P$ 's $<0.05)$. There were no differences in educational attainment between those who completed and those who did not complete the LAQ measure at baseline [35].

\subsection{Measures}

2.2.1. Education. Educational attainment was defined as the self-reported number of years of formal education completed. 
2.2.2. Activity. Frequency of participation in a wide range of activities was assessed via the Lifestyle Activities Questionnaire [16]. Participants rated their typical frequency of participation in various daily activities (e.g., cooking, singing, gardening, listening to music, reading) over the past year. Responses were made on a 6-point scale (never/less often than once a month, once a month, 2 to 3 times a month, once a week, a few times a week, and every day).

For analyses, we classified lifestyle activities into five activity domains to examine the effects of participation in specific types of activity on education-cognition relations (Table 2; also see Parisi et al. [35] for detailed information on activity items and domains). These activity domains were theoretically based on a comprehensive review of the existing literature $[10,12,14,16,22,36,37]$ and have been used in our previous research [35]. Specifically, individual activity items were classified into intellectual (6 items: reading a book, reading a newspaper, balancing checkbook, using a computer, crossword puzzles, taking courses/classes), social (7 items: discussing local or national issues, visiting, clubs/organizations, attending church/religious service, playing cards/games, going to movies, going to plays/concerts), physical (3 items: shopping, gardening, hunting/fishing/camping), creative (4 items: singing, playing an instrument, cooking, drawing or painting, sewing/mending/fixing things), and passive (4 items: watching TV, listening to music, listening to the radio (not music), looking at art) activity domains (Table 2). The frequency of participation was calculated within each activity domain by averaging frequency responses to individual activity items, with lower numbers reflecting less participation.

2.2.3. Cognition. Measures were selected to assess global cognitive status (MMSE) [32] and several distinct cognitive processes, such as reading ability, processing speed, and memory performance. Reading ability was assessed using the reading subtest of the Wide Range Achievement Test, version 4 (WRAT-4) [33]. To complete this test, participants are asked to read aloud a list of 15 letters and 55 words increasing in difficulty level (from cat to terpsichorean). Higher scores reflect a greater number of correctly pronounced words. Processing speed was assessed by the pattern comparison task [38] in which participants are asked to make "same" or "different" judgments as quickly as possible (for 30 seconds) for sequences of pairs of patterns. Higher scores reflect a greater number of correct responses. Memory performance was assessed by the Rey Auditory Verbal Learning Test (AVLT) $[39,40]$, capturing both immediate and delayed recall. Using a word-list learning paradigm, participants are first presented with a 15-word list (List A) and asked to recall the list (this process is repeated for five trials). Next, participants are presented with one trial of a second 15word list (List B; interference) and asked to recall the list. Finally, participants are asked to recall the words on the initial list (List A) after a 20-minute delay (delayed recall trial). For scoring, immediate recall reflects the sum of words recalled on trials 1 to 5 (on List A) and delayed recall reflects total number of words recalled after a 20-minute delay. For
TABLE 2: Activity domains from the lifestyle activities questionnaire.

\begin{tabular}{|c|c|c|c|}
\hline Activities & $\begin{array}{l}\text { Percentage of } \\
\text { individuals } \\
\text { reporting activity }\end{array}$ & M & SD \\
\hline \multicolumn{4}{|l|}{ Intellectual } \\
\hline Reading a book & 88.7 & 3.1 & 1.8 \\
\hline Reading a newspaper & 87.7 & 3.6 & 1.7 \\
\hline Balancing checkbook & 82.6 & 2.0 & 1.5 \\
\hline Using a computer & 57.0 & 2.2 & 2.2 \\
\hline Crossword puzzles & 49.0 & 1.6 & 2.0 \\
\hline Taking courses or classes & 25.7 & 0.6 & 1.2 \\
\hline \multicolumn{4}{|l|}{ Social } \\
\hline Discussing local or national issues & 96.0 & 3.9 & 1.3 \\
\hline Attending church religious service & 91.3 & 3.0 & 1.3 \\
\hline Visiting & 87.2 & 2.3 & 1.4 \\
\hline Clubs/organizations & 78.6 & 2.2 & 1.6 \\
\hline Playing cards or games & 49.4 & 1.2 & 1.5 \\
\hline Going to movies & 33.9 & 0.5 & 0.9 \\
\hline Going to plays concerts & 33.5 & 0.4 & 0.7 \\
\hline \multicolumn{4}{|l|}{ Physical } \\
\hline Shopping & 98.8 & 3.3 & 1.0 \\
\hline Gardening & 46.9 & 1.5 & 1.8 \\
\hline Hunting, Fishing, Camping & 3.7 & 0.1 & 0.3 \\
\hline \multicolumn{4}{|l|}{ Creative } \\
\hline Preparing food & 97.6 & 4.2 & 1.1 \\
\hline Sewing, mending, fixing things & 78.2 & 2.2 & 1.6 \\
\hline Singing, playing instrument & 66.6 & 2.5 & 2.0 \\
\hline Drawing or Painting & 21.0 & 0.5 & 1.1 \\
\hline \multicolumn{4}{|l|}{ Passive } \\
\hline Watching TV & 99.1 & 4.8 & 0.6 \\
\hline Listening to music & 99.1 & 4.6 & 0.9 \\
\hline Listening to radio (not music) & 89.3 & 3.8 & 1.6 \\
\hline Looking at art & 58.9 & 1.4 & 1.6 \\
\hline
\end{tabular}

Note: Averages based on 6-point scale; 1 = never, 6 = everyday.

each of these outcome measures, higher scores reflect greater memory ability.

2.2.4. Covariates. Final models adjusted for demographics (e.g., age, sex, ethnicity/race), household income (for the past 12 months), self-reported health status (5-point scale; $1=$ poor to $5=$ excellent), and depressive symptoms as measured by the Geriatric Depression Scale (15-item) [34].

2.3. Data Analysis. Multiple mediation models were applied to determine the following: (1) whether frequent participation in a wide range of lifestyle activities could partially explain the relationship between education and cognition, or (2) whether the relationship between education and cognition could be better explained by participation in specific activity domains (see Figure 1) [41, 42]. As we were 


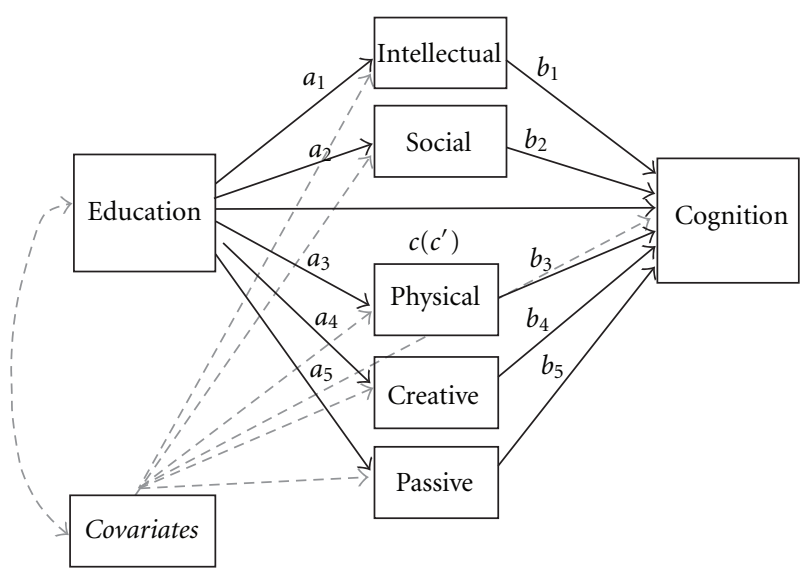

Figure 1: Example of multiple mediator model.

interested in exploring the relative contributions of education and activities on distinct cognitive abilities, multiple mediation models were conducted separately for each cognitive outcome (e.g., reading ability, processing speed, memory; Figure 1). Analyses were conducted with IBM Statistical Package for the Social Sciences (SPSS) software, version 19 (see http://www.quantpsy.org/ for the SPSS macro command set for multiple mediation) [42].

Following the procedures defined by Preacher and Hayes [42], we examined both the total and specific indirect effects using 5,000 bootstrap samples to calculate the 95\% biascorrected and accelerated bootstrap confidence intervals (CI). These nonparametric bootstrapping techniques are often considered more statistically robust than traditional approaches (e.g., Sobel test, causal steps approach) because they do not assume normality in the sampling distribution [42-45]. The total indirect effect explains the combined contribution of activity domains (intellectual, social, physical, creative, passive) on education-cognition relations; whereas, the specific indirect effect tests the unique contribution of each activity domain, above and beyond participation in other domains. Point estimates were considered significant when zero was not included in the confidence interval.

\section{Results}

3.1. Correlations. As expected, greater educational attainment was related to better performance on cognitive measures (ranging from $r=0.09$ for processing speed to $r=$ 0.46 for reading ability), as well as with overall frequency of activity $(r=0.14)$ (Table 3$)$. Educational attainment was also related to greater participation in intellectual and physical activities ( $r=0.26$ and 0.14 , resp.). Additionally, greater participation in intellectual activities was consistently associated with performance on cognitive tasks (ranging from $r=0.11$ for delayed memory recall to $r=0.22$ for reading ability).

3.2. Multiple Mediation Models. The results from the bootstrapping analyses showed that the total indirect effect (i.e., aggregate effect of participation across the five activity domains) was significant for the measures of global cognition (point estimate $\left.=0.120 ; \mathrm{CI}_{.95}=0.000,0.025\right)$, reading ability (point estimate $\left.=0.062 ; \mathrm{CI}_{.95}=0.014,0.120\right)$, and processing speed (point estimate $=0.075 ; \mathrm{CI}_{.95}=0.033,0.131$ ) $($ Table 4$)$. It is important to note that in each of these models, education-cognition relations were not completely eliminated (i.e., the association between education on cognition remained significant). These findings indicate that, taken as a set, frequent participation in a wide range of lifestyle activities partially accounts for the effects of education on these cognitive abilities. Further inspection of the specific indirect effects (e.g., $a_{1} b_{1}$ versus $a_{2} b_{2}$ in Figure 1 ) indicated that this effect only held true for intellectually challenging activities (point estimate $=0.014 ; \mathrm{CI}_{.95}=0.000,0.025$ for global cognition; point estimate $=0.070 ; \mathrm{CI}_{.95}=0.027,0.125$ for reading ability; point estimate $=0.078 ; \mathrm{CI}_{.95}=0.040$, 0.134 for processing speed; Table 4), controlling for all other activity domains. Thus, these findings suggest that greater participation in social, physical, creative, or passive activity did not contribute to the total indirect effect above and beyond participation in intellectual activity for measures of global cognition, reading ability, and processing speed. We did not find similar associations (neither the total nor specific indirect effects were significant) for the AVLT immediate or delayed memory task.

\section{Discussion}

The goal of the present study was to examine whether participation in a wide range of activities (intellectual, social, physical, creative, and passive) could account for the relationship between education and cognition in adulthood. Generally, our findings suggest that education-cognition relations can be partially explained by frequent participation in intellectual demanding activities $[19,29,46]$.

As suggested earlier, educational experiences may provide the necessary knowledge, understanding, skills, and competencies for establishing a lifetime of participation in cognitive challenges. In fact, individuals with higher levels of educational attainment tend to allocate more time and put forth more effort when engaging in intellectually complex activities [47]. As a result, the accumulated exposure to cognitively charged environments may have a direct beneficial effect on brain structure and function, resulting in greater neurological development (e.g., increase in synaptic density) or more efficient use of existing brain networks [48-50]. In addition to such neuroprotective effects, continued practice of cognitive skills may develop compensatory strategies to help maintain cognition in the face of age-related declines [51] or may bolster perceptions of confidence and competence in one's skills and abilities, potentially leading to more frequent engagement in cognitively demanding environments $[36,52]$.

It is important to mention, however, that the association between education and cognition was not completely eliminated by participation in intellectually demanding activities, suggesting that both educational attainment and intellectual endeavors may independently benefit late-life cognitive 
TABLE 3: Unadjusted correlations among education, activity, and cognition.

\begin{tabular}{lcccccc}
\hline & Education & MMSE & WRAT-4 & $\begin{array}{l}\text { Cognition } \\
\text { Speed }\end{array}$ & Memory: immediate & Memory: delayed \\
\hline $\begin{array}{l}\text { Education } \\
\text { Activity level }\end{array}$ & 1.00 & $0.17^{* *}$ & $0.46^{* *}$ & $0.09^{*}$ & $0.10^{* *}$ & $0.11^{* *}$ \\
$\quad \begin{array}{l}\text { Frequency, overall } \\
\text { Activity type }\end{array}$ & $0.14^{* *}$ & $0.08^{*}$ & 0.05 & $0.15^{* *}$ & $0.12^{* *}$ & $0.10^{*}$ \\
$\quad$ Intellectual & & & & & & $0.11^{* *}$ \\
$\quad$ Social & $0.26^{* *}$ & $0.12^{* *}$ & $0.22^{* *}$ & $0.16^{* *}$ & $0.14^{* *}$ & 0.03 \\
Physical & -0.04 & -0.01 & $-0.13^{* *}$ & $0.08^{*}$ & 0.05 & 0.01 \\
Creative & $0.14^{* *}$ & -0.03 & $0.08^{*}$ & 0.04 & 0.04 & $0.10^{*}$ \\
$\quad$ Passive & 0.01 & 0.02 & -0.06 & 0.06 & $0.12^{* *}$ & -0.01 \\
\hline
\end{tabular}

Note: ${ }^{*} P<0.05 .{ }^{* *} P<0.01$. MMSE: Mini-Mental State Exam; WRAT: Wide Range Achievement Test- 4 .

performance [29]. In other words, although education may provide a foundation for continued engagement in intellectually demanding environments across the life course, it is also the "choices we make, not chance, that determines our fate" [53].

The few studies that have previously investigated these hypothesized pathways have yielded mixed findings. Similar to our findings, Kleigel and colleagues [29] also demonstrated the importance of both education and intellectual stimulation for cognitive performance among the oldest old. A more recent study by Soubelet [54], however, failed to find such associations. The discrepancies may be attributable, in part, to differences in the selected sample, exclusively among centenarians $(\mathrm{M}=100.21$ years; $\mathrm{SD}=0.40)$ [29] or across a large range of ages (18-96 years) [54]. Further, the definition of intellectual activity differed across studies, potentially impacting the significance of findings. For instance, some of the intellectual activities used in the study by Soubelet [54] were included in our social domain (e.g., theater, cinema, religious participation), for which we did not find significant associations. It should also be noted that the few reports examining whether education-cognition associations could be explained by intellectual activities did not simultaneously consider participation in other forms of engagement. In fact, there is very little work that has examined the relations between education and the types of lifestyle activities that were measured in the current study. The application of multiple mediation models allowed us to test the effects of participation in a wide range of activities (total indirect effect), as well as independent associations with specific activity domains (specific indirect effect), on cognitive performance. To our knowledge, no other study has explored whether participation in various forms of activity can potentially explain the association between education and cognition.

Although our findings contribute to the relatively few studies that have examined education-cognition pathways, several limitations need to be addressed. First and foremost, as our data were cross-sectional, we were unable to distinguish whether variation in cognition resulted from agerelated decline or from earlier life experiences. We also were unable to establish temporal precedence between activity and cognition. As such, it is also likely that cognitive ability could lead to greater activity [23, 55], rather than activity driving cognition as suggested in the current study. With this said, while correlation does not imply causation, establishing covariation among variables is a necessary (albeit insufficient) condition for causality. In the literature, several questions reg4rding the determinants and effects of an active lifestyle have yet to be answered [15]. Even though we cannot draw causal assumptions from crosssectional data, our correlational findings help define what causal models are plausible. More longitudinal investigations are needed to test these competing models, as well as to determine how engaging in cognitively complex challenges across different periods of the lifespan impacts cognition in adulthood $[21,56]$.

We also acknowledge that investigating these associations within the context of a school-based, intensive volunteer program attracted a relatively healthy, active group of volunteers potentially limits the generalizability of our findings to other populations. However, individuals included in this study reported a high prevalence of chronic health conditions (e.g., diabetes, stroke, hypertension, and vascular disease) and comorbidity, placing them at a disproportionately greater risk for cognitive and physical impairments [57]. We also recognize that the number of years of education does not directly translate to the quality of these educational experiences $[58,59]$. This is especially salient given that many of the individuals enrolled in the Baltimore Experience Corps Trial were educated prior to desegregation, a time when the quality of and access to education was not equal for African Americans.

Lastly, our measure of activity (LAQ) was developed to capture participation in a broad range of lifestyle activities (e.g., cognitive, social, physical), with a limited number of items reflecting each activity domain. This is especially true for physical activities, which have demonstrated associations with both education and cognition in prior research [48]. However, these neurobiological findings have not translated as well to epidemiologic studies of dementia risk, where self-reported frequency of physical activity is the standard $[60,61]$. For instance, Wang and colleagues [62] did not observe an association between physical activity and dementia incidence after accounting for participation in social, cognitive, and productive activities. Nonetheless, findings may have differed if more extensive activity measures were 
TABLE 4: Indirect effects of education on cognition through activity.

\begin{tabular}{|c|c|c|c|c|}
\hline \multirow[b]{2}{*}{ Indirect effects } & \multirow[b]{2}{*}{ Estimate } & \multirow[b]{2}{*}{ SE } & \multicolumn{2}{|c|}{ BCa $95 \% \mathrm{Cl}$} \\
\hline & & & Lower & Upper \\
\hline \multicolumn{5}{|c|}{ MMSE } \\
\hline Total & .012 & .006 & .000 & .025 \\
\hline Intellectual & .014 & .006 & .003 & .027 \\
\hline Social & .000 & .001 & -.003 & .003 \\
\hline Physical & -.002 & .002 & -.008 & .002 \\
\hline Creative & -.001 & .001 & -.005 & .001 \\
\hline Passive & -.001 & .002 & -.006 & .001 \\
\hline \multicolumn{5}{|c|}{ WRAT-4 } \\
\hline Total & .062 & .027 & .014 & .120 \\
\hline Intellectual & .070 & .024 & .027 & .125 \\
\hline Social & .000 & .004 & -.010 & .009 \\
\hline Physical & .003 & .009 & -.011 & .027 \\
\hline Creative & -.004 & .008 & -.029 & .005 \\
\hline Passive & -.007 & .009 & -.033 & .004 \\
\hline \multicolumn{5}{|c|}{ Processing speed } \\
\hline Total & .075 & .025 & .033 & .131 \\
\hline Intellectual & .078 & .024 & .040 & .134 \\
\hline Social & .000 & .004 & -.007 & .007 \\
\hline Physical & .001 & .008 & -.016 & .018 \\
\hline Creative & .001 & .004 & -.007 & .012 \\
\hline Passive & -.004 & .007 & -.025 & .003 \\
\hline \multicolumn{5}{|c|}{ Memory: immediate recall } \\
\hline Total & .043 & .033 & -.015 & .112 \\
\hline Intellectual & .050 & .031 & -.004 & .119 \\
\hline Social & .002 & .005 & -.009 & .012 \\
\hline Physical & -.004 & .012 & -.033 & .017 \\
\hline Creative & .004 & .010 & -.006 & .036 \\
\hline Passive & -.008 & .010 & -.041 & .004 \\
\hline \multicolumn{5}{|c|}{ Memory: delayed recall } \\
\hline Total & .005 & .012 & -.017 & .030 \\
\hline Intellectual & .010 & .012 & -.012 & .034 \\
\hline Social & .000 & .002 & -.005 & .004 \\
\hline Physical & -.005 & .005 & -.018 & .002 \\
\hline Creative & .001 & .003 & -.002 & .012 \\
\hline Passive & -.001 & .003 & -.012 & .002 \\
\hline
\end{tabular}

Note: IV: independent variable (education, in years); DV: dependent variable (cognitive outcomes); BCa 95\% Cl: bias-corrected and accelerated confidence intervals. Total indirect effect represents the sum of the indirect effects for specific activity pathways. All models were adjusted for age, sex, race, household income (past 12 months), health, and depression.

implemented. Further, education and lifestyle activities are not the only forms of experiential richness. For instance, occupational complexity has been consistently linked to cognition in later life [56, 63]. Moreover, occupational status is often associated with other factors (e.g., finances, time) that may impact selection and participation in activities over the life course [64]. Unfortunately, we did not have a reliable measure of occupational history or complexity and were unable to explore these relations in our dataset.

Consistent with the engagement hypothesis [3, 10], remaining actively engaged in activities may provide a protective mechanism against cognitive decline and dementia in later life. Although there was some evidence that education-cognition relations could be partially explained by greater participation in intellectual activities, both education and activities uniquely contributed to cognition in adulthood. As such, interventions such as the Experience Corps program which promote broad-based engagement may help older adults maintain, or potentially enhance, cognitive function. Further research is recommended to replicate these important findings with similar activities in varied populations. 


\section{Acknowledgments}

Funding for the Experience Corps Trial was provided in part by NIA P01 AG027735, the John A. Hartford Foundation, and by the Johns Hopkins Older Americans Independence Center under Contracts P30-AG02133 and R37-AG19905 from the National Institute on Aging, National Institutes of Health. During early phases of this research, Dr. J.M. Parisi was supported, in part, by a National Institute of Mental Health Prevention Research Training Grant (T-32 MH018834; Nicholas Ialongo, Principal Investigator). The authors would also like to thank the Greater Homewood Community Corporation, Experience Corps National, Civic Ventures, the Baltimore City Public School System, the City of Baltimore, the Commission on Aging and Retirement Education, the Baltimore City Retirees Association, AARP, the Harry and Jeanette Weinberg Foundation, and The John D. and Catherine T. MacArthur Foundation for ongoing vision and support.

\section{References}

[1] M. S. Albert, K. Jones, C. R. Savage et al., "Predictors of cognitive change in older persons: MacArthur studies of successful aging," Psychology and Aging, vol. 10, no. 4, pp. 578589, 1995.

[2] C. G. Lyketsos, L. S. Chen, and J. C. Anthony, "Cognitive decline in adulthood: an 11.5-year follow-up of the Baltimore Epidemiologic Catchment Area study," American Journal of Psychiatry, vol. 156, no. 1, pp. 58-65, 1999.

[3] K. W. Schaie, Developmental Influences on Adult Intelligence: The Seattle Longitudinal Study, Oxford University Press, New York, NY, USA, 2005.

[4] E. M. Tucker-Drob, K. E. Johnson, and R. N. Jones, "The cognitive reserve hypothesis: a longitudinal examination of age-associated declines in reasoning and processing speed," Developmental Psychology, vol. 45, no. 2, pp. 431-446, 2009.

[5] R. S. Wilson, L. E. Hebert, P. A. Scherr, L. L. Barnes, C. F. M. De Leon, and D. A. Evans, "Educational attainment and cognitive decline in old age," Neurology, vol. 72, no. 5, pp. 460465, 2009.

[6] D. A. Bennett, R. S. Wilson, J. A. Schneider et al., "Education modifies the relation of $\mathrm{AD}$ pathology to level of cognitive function in older persons," Neurology, vol. 60, no. 12, pp. 1909-1915, 2003.

[7] M. C. Carlson, J. Brandt, K. A. Carson, and C. H. Kawas, "Lack of relation between race and cognitive test performance in Alzheimer's disease," Neurology, vol. 50, no. 5, pp. 1499-1501, 1998.

[8] E. S. Sharp and M. Gatz, "Relationship between education and dementia: an updated systematic review," Alzheimer Disease of Associated Disorders, vol. 25, pp. 289-304, 2011.

[9] Y. Stern, B. Gurland, T. K. Tatemichi, Ming Xin Tang, D. Wilder, and R. Mayeux, "Influence of education and occupation on the incidence of Alzheimer's disease," Journal of the American Medical Association, vol. 271, no. 13, pp. 1004-1010, 1994.

[10] D. F. Hultsch, C. Hertzog, B. J. Small, and R. A. Dixon, "Use it or lose it: engaged lifestyle as a buffer of cognitive decline in aging?" Psychology and Aging, vol. 14, no. 2, pp. 245-263, 1999.

[11] L. A. Strain, C. C. Grabusic, M. S. Searle, and N. J. Dunn, "Continuing and ceasing leisure activities in later life: a longitudinal study," Gerontologist, vol. 42, no. 2, pp. 217-223, 2002.

[12] M. J. Aartsen, C. H. M. Smits, T. Van Tilburg, K. C. P. M. Knipscheer, and D. J. H. Deeg, "Activity in older adults: cause or consequence of cognitive functioning? A longitudinal study on everyday activities and cognitive performance in older adults," Journals of Gerontology, vol. 57, no. 2, pp. P153-P162, 2002.

[13] M. E. Lachman, S. Agrigoroaei, C. Murphy, and P. A. Tun, "Frequent cognitive activity compensates for education differences in episodic memory," American Journal of Geriatric Psychiatry, vol. 18, no. 1, pp. 4-10, 2010.

[14] R. S. Wilson, D. A. Bennett, L. A. Beckett et al., "Cognitive activity in older persons from a geographically defined population," Journals of Gerontology, vol. 54, no. 3, pp. P155P160, 1999.

[15] A. A. M. Bielak, "How can we not 'lose it' if we still don't understand how to 'use it'? unanswered questions about the influence of activity participation on cognitive performance in older age-a mini-review," Gerontology, vol. 56, no. 5, pp. 507519, 2010.

[16] M. C. Carlson, J. M. Parisi, J. Xia et al., "Lifestyle activities and aging: variety may be the spice of life," Journal of the International Neuropsychological Society, vol. 18, pp. 1-9, 2011.

[17] C. Hertzog, A. F. Kramer, R. S. Wilson, and U. Lindenberger, "Enrichment effects on adult cognitive development: can the functional capacity of older adults be preserved and enhanced?" Psychological Science in the Public Interest, Supplement, vol. 9, no. 1, pp. 1-65, 2008.

[18] E. A. L. Stine-Morrow, J. M. Parisi, D. G. Morrow, and D. C. Park, "The effects of an engaged lifestyle on cognitive vitality: a field experiment," Psychology and Aging, vol. 23, no. 4, pp. 778786, 2008.

[19] R. S. Wilson, L. L. Barnes, K. R. Krueger, G. Hoganson, J. L. Bienias, and D. A. Bennett, "Early and late life cognitive activity and cognitive systems in old age," Journal of the International Neuropsychological Society, vol. 11, no. 4, pp. 400-407, 2005.

[20] M. Lövdén, L. Bäckman, U. Lindenberger, S. Schaefer, and F. Schmiedek, "A theoretical framework for the study of adult cognitive plasticity," Psychological Bulletin, vol. 136, no. 4, pp. 659-676, 2010.

[21] C. Schooler and M. S. Mulatu, "The reciprocal effects of leisure time activities and intellectual functioning in older people: a longitudinal analysis," Psychology and Aging, vol. 16, no. 3, pp. 466-482, 2001.

[22] A. A. M. Bielak, T. F. Hughes, B. J. Small, and R. A. Dixon, "It's never too late to engage in lifestyle activities: significant concurrent but not change relationships between lifestyle activities and cognitive speed," Journals of Gerontology, vol. 62, no. 6, pp. P331-P339, 2007.

[23] B. J. Small, R. A. Dixon, J. J. McArdle, and K. J. Grimm, "Do changes in lifestyle engagement moderate cognitive decline in normal aging? Evidence from the Victoria Longitudinal Study," Neuropsychology, vol. 26, pp. 144-155, 2012.

[24] R. S. Wilson, L. L. Barnes, and D. A. Bennett, "Assessment of lifetime participation in cognitively stimulating activities," Journal of Clinical and Experimental Neuropsychology, vol. 25, no. 5, pp. 634-642, 2003.

[25] P. Ghisletta, J. F. Bickel, and M. Lövdén, "Does activity engagement protect against cognitive decline in old age? Methodological and analytical considerations," Journals of Gerontology, vol. 61, no. 5, pp. P253-P261, 2006. 
[26] J. Y. J. Wang, D. H. D. Zhou, J. Li et al., "Leisure activity and risk of cognitive impairment: the Chongqing aging study," Neurology, vol. 66, no. 6, pp. 911-913, 2006.

[27] R. S. Wilson, D. A. Bennett, D. W. Gilley, L. A. Beckett, L. L. Barnes, and D. A. Evans, "Premorbid reading activity and patterns of cognitive decline in Alzheimer disease," Archives of Neurology, vol. 57, no. 12, pp. 1718-1723, 2000.

[28] T. Fritsch, M. J. McClendon, K. A. Smyth, A. J. Lerner, R. P. Friedland, and J. D. Larsen, "Cognitive functioning in healthy aging: the role of reserve and lifestyle factors early in life," Gerontologist, vol. 47, no. 3, pp. 307-322, 2007.

[29] M. Kliegel, D. Zimprich, and C. Rott, "Life-long intellectual activities mediate the predictive effect of early education on cognitive impairment in centenarians: a retrospective study," Aging and Mental Health, vol. 8, no. 5, pp. 430-437, 2004.

[30] L. P. Fried, M. C. Carlson, M. Freedman et al., "A social model for health promotion for an aging population: initial evidence on the Experience Corps model," Journal of Urban Health, vol. 81, no. 1, pp. 64-78, 2004.

[31] G. W. Rebok, M. C. Carlson, T. A. Glass et al., "Short-term impact of Experience Corps participation on children and schools: results from a pilot randomized trial," Journal of Urban Health, vol. 81, no. 1, pp. 79-93, 2004.

[32] M. F. Folstein, S. E. Folstein, and P. R. McHugh, "'Mini mental state. A practical method for grading the cognitive state of patients for the clinician," Journal of Psychiatric Research, vol. 12, no. 3, pp. 189-198, 1975.

[33] G. S. Wilkinson and G. J. Robertson, Wide Range Achievement Test-Fourth Edition, Psychological Assessment Resources, Lutz, Fla, USA, 2006.

[34] J. I. Sheikh and J. A. Yesavage, "Geriatric Depression Scale (GDS): recent evidence and development of a shorter version," Clinical Gerontologist, vol. 5, no. 1-2, pp. 165-173, 1986.

[35] J. M. Parisi, G. W. Rebok, T. E. Seeman, E. K. Tanner, E. Tan, and L. P. Fried, "Lifestyle activities in sociodemographically atrisk urban, older adults prior to participation in the Baltimore Experience Corps trial," Activities, Adaptation, and Aging. In press.

[36] D. Jopp and C. Hertzog, "Activities, self-referent memory beliefs, and cognitive performance: evidence for direct and mediated relations," Psychology and Aging, vol. 22, no. 4, pp. 811-825, 2007.

[37] J. M. Parisi, E. A. Stine-Morrow, S. R. Noh, and D. G. Morrow, "Predispositional engagement, activity engagement, and cognition among older adults," Neuropsychology, Development, and Cognition, vol. 16, no. 4, pp. 485-504, 2009.

[38] T. A. Salthouse and R. L. Babcock, "Decomposing adult age differences in working memory," Developmental Psychology, vol. 27, no. 5, pp. 763-776, 1991.

[39] A. Rey, "L'examen psychologique dans les cas d'encephalopathie tramatique," Archives de Psychologie, vol. 28, pp. 286-340, 1941.

[40] M. Schmidt, Rey Auditory and Verbal Learning Test: A Handbook, Western Psychological Services, Los Angeles, Calif, USA, 2004.

[41] D. P. MacKinnon, "Contrasts in multiple mediator models," in Multivariate Applications in Substance Use Research: New Methods for New Questions, J. S. Rose, L. Chassin, C. C. Presson, and S. J. Sherman, Eds., pp. 141-160, Erlbaum, Mahwah, NJ, USA, 2000.

[42] K. J. Preacher and A. F. Hayes, "Asymptotic and resampling strategies for assessing and comparing indirect effects in multiple mediator models," Behavior Research Methods, vol. 40, no. 3, pp. 879-891, 2008.
[43] D. P. MacKinnon, C. M. Lockwood, J. M. Hoffman, S. G. West, and V. Sheets, "A comparison of methods to test mediation and other intervening variable effects," Psychological Methods, vol. 7, no. 1, pp. 83-104, 2002.

[44] P. E. Shrout and N. Bolger, "Mediation in experimental and nonexperimental studies: new procedures and recommendations," Psychological Methods, vol. 7, no. 4, pp. 422-445, 2002.

[45] J. Williams and D. P. MacKinnon, "Resampling and distribution of the product methods for testing indirect effects in complex models," Structural Equation Modeling, vol. 15, no. 1, pp. 23-51, 2008.

[46] T. Y. Arbuckle, D. P. Gold, J. S. Chaikelson, and S. Lapidus, "Measurement of activity in the elderly: the activities checklist," Canadian Journal on Aging, vol. 13, no. 4, pp. 550-565, 1994.

[47] J. M. Parisi, "Engagement in adulthood: perceptions and participation in daily activities," Activities, Adaptation and Aging, vol. 34, no. 1, pp. 1-16, 2010.

[48] S. Colcombe and A. F. Kramer, "Fitness effects on the cognitive function of older adults: a meta-analytic study," Psychological Science, vol. 14, no. 2, pp. 125-130, 2003.

[49] D. C. Park and P. Reuter-Lorenz, "The adaptive brain: aging and neurocognitive scaffolding," Annual Review of Psychology, vol. 60, pp. 173-196, 2009.

[50] N. Scarmeas and Y. Stern, "Cognitive reserve: implications for diagnosis and prevention of Alzheimer's disease," Current Neurology and Neuroscience Reports, vol. 4, no. 5, pp. 374-380, 2004.

[51] P. B. Baltes and M. M. Baltes, "Selective optimization with compensation," in Successful Aging: Perspectives from the Behavioral Sciences, P. B. Baltes and M. M. Baltes, Eds., Cambridge University Press, New York, NY, USA, 1990.

[52] M. E. Lachman, "Perceived control over aging-related declines: adaptive beliefs and behaviors," Current Directions in Psychological Science, vol. 15, no. 6, pp. 282-286, 2006.

[53] E. A. L. Stine-Morrow, "The dumbledore hypothesis of cognitive aging," Current Directions in Psychological Science, vol. 16, no. 6, pp. 295-299, 2007.

[54] A. Soubelet, "Engaging in cultural activities compensates for educational differences in cognitive abilities," Aging, Neuropsychology, and Cognition, vol. 18, pp. 516-526, 2011.

[55] A. J. Gow, J. Corley, J. M. Starr, and I. J. Deary, "Reverse causation in activity-cognitive ability associations: the Lothian Birth Cohort 1936," Psychology and Aging, vol. 27, pp. 250255, 2012.

[56] C. Schooler, M. S. Mulatu, and G. Oates, "The continuing effects of substantively complex work on the intellectual functioning of older workers," Psychology and Aging, vol. 14, no. 3, pp. 483-506, 1999.

[57] Alzheimer's Association, Alzheimer's Disease Facts and Figures, Alzheimer's Association, Chicago, Ill, USA, 2010.

[58] J. J. Manly, D. M. Jacobs, P. Touradji, S. A. Small, and Y. Stern, "Reading level attenuates differences in neuropsychological test performance between African American and White elders," Journal of the International Neuropsychological Society, vol. 8, no. 3, pp. 341-348, 2002.

[59] J. J. Manly, P. Touradji, M. X. Tang, and Y. Stern, "Literacy and memory decline among ethnically diverse elders," Journal of Clinical and Experimental Neuropsychology, vol. 25, no. 5, pp. 680-690, 2003.

[60] L. J. Podewils, E. Guallar, L. H. Kuller et al., "Physical activity, APOE genotype, and dementia risk: findings from the 
Cardiovascular Health Cognition Study," American Journal of Epidemiology, vol. 161, no. 7, pp. 639-651, 2005.

[61] J. Verghese, R. B. Lipton, M. J. Katz et al., "Leisure activities and the risk of dementia in the elderly," New England Journal of Medicine, vol. 348, no. 25, pp. 2508-2516, 2003.

[62] H. X. Wang, A. Karp, B. Winblad, and L. Fratiglioni, "Late-life engagement in social and leisure activities is associated with a decreased risk of dementia: a longitudinal study from the Kungsholmen Project," American Journal of Epidemiology, vol. 155, no. 12, pp. 1081-1087, 2002.

[63] R. Andel, M. Crowe, I. Kareholt, J. Wastesson, and M. G. Parker, "Indicators of job strain at midlife and cognitive functioning in advanced old age," Journals of Gerontology, vol. 66, no. 3, pp. 287-291, 2011.

[64] A. F. Kramer, L. Bherer, S. J. Colcombe, W. Dong, and W. T. Greenough, "Environmental influences on cognitive and brain plasticity during aging," Journals of Gerontology, vol. 59, no. 9, pp. 940-957, 2004. 


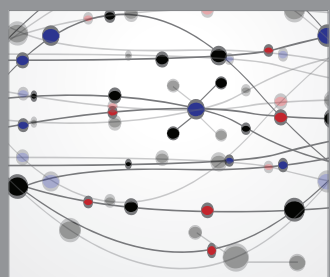

The Scientific World Journal
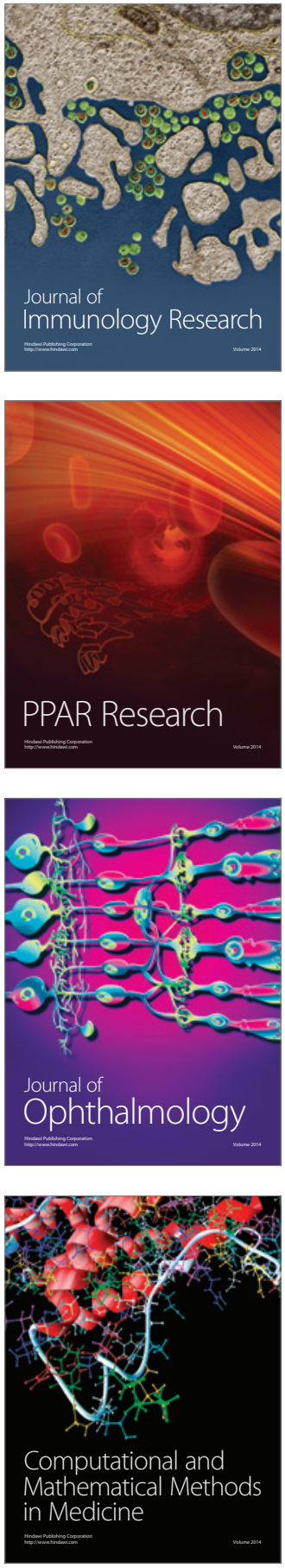

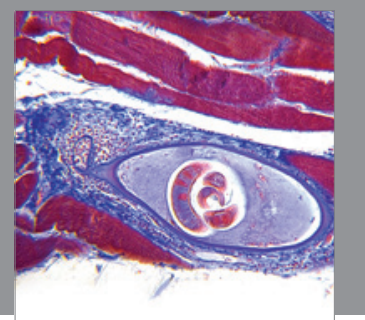

Gastroenterology

Research and Practice
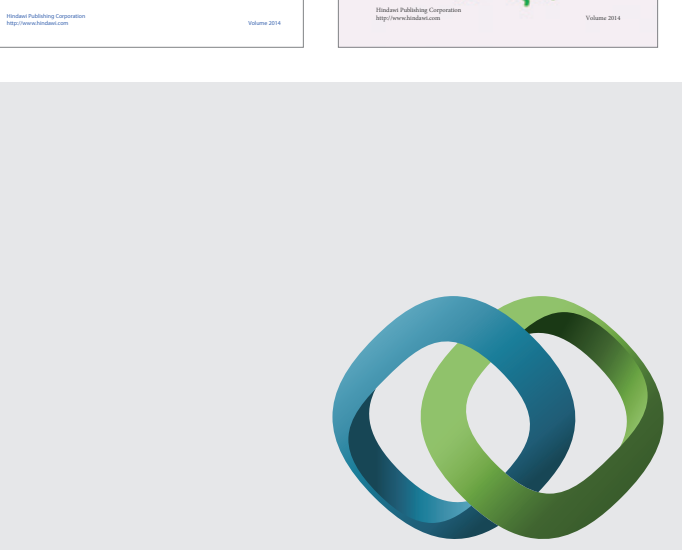

\section{Hindawi}

Submit your manuscripts at

http://www.hindawi.com
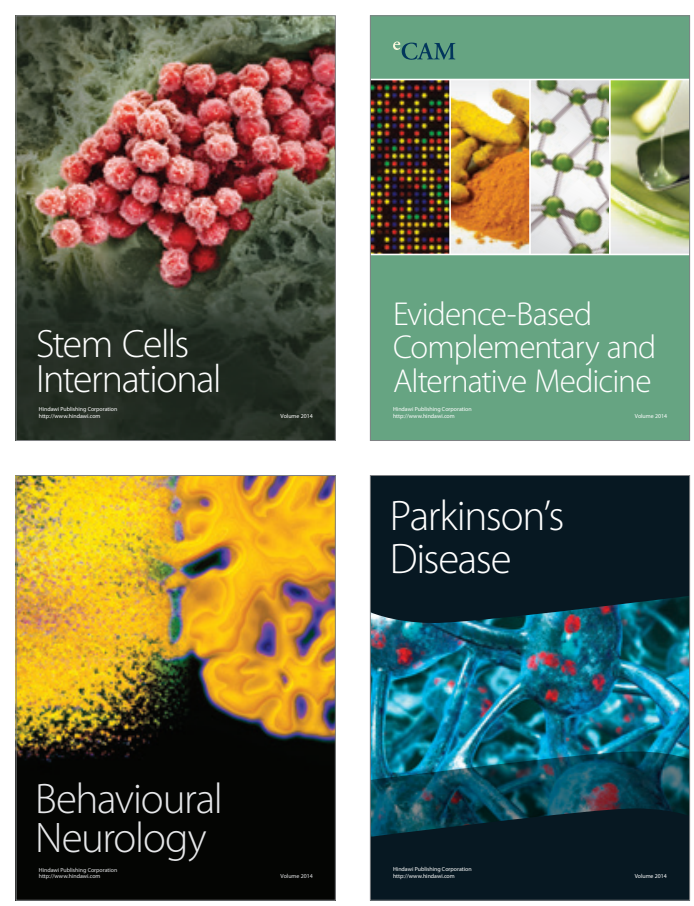

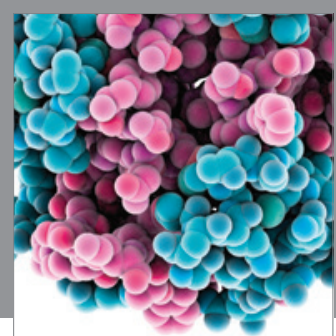

Journal of
Diabetes Research

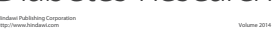

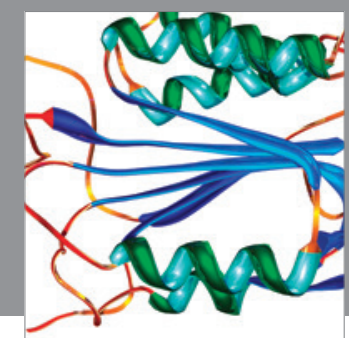

Disease Markers
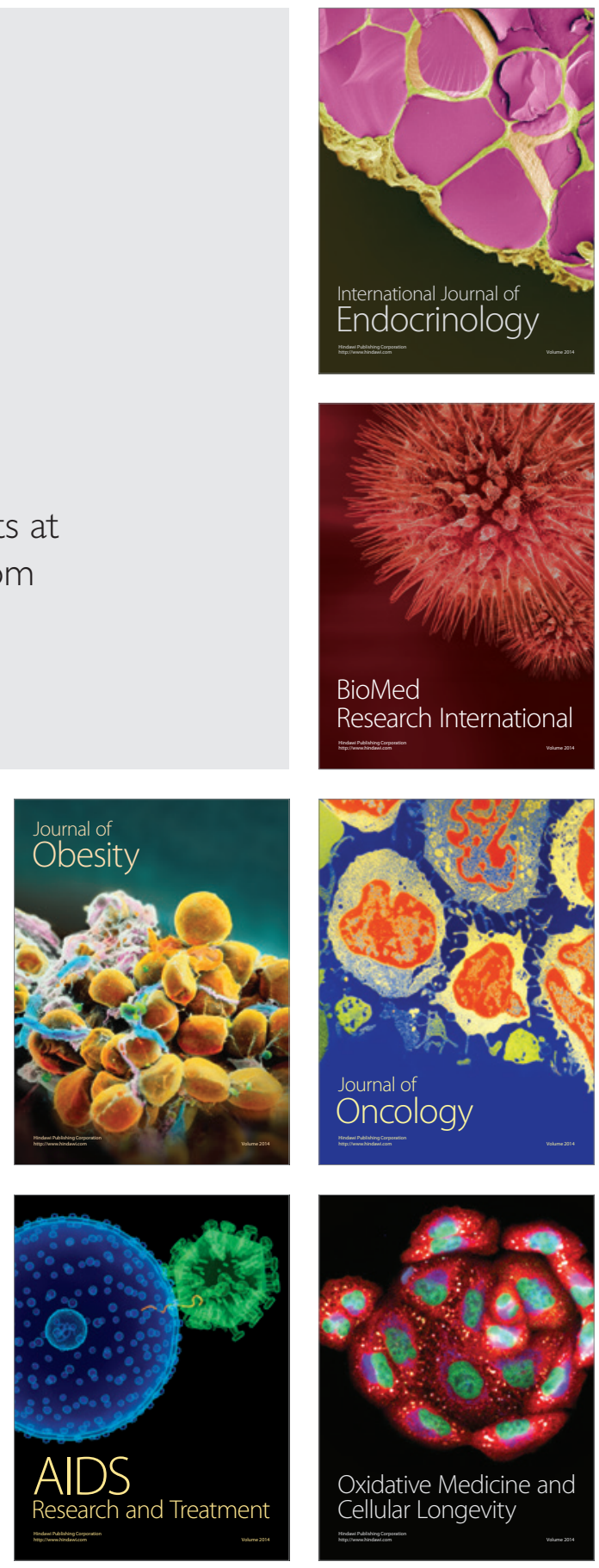